\title{
Figurative Pottery in Prehistoric Iran
}

\author{
by \\ NAMIO EGAMI \\ Professor of Tokyo University
}

The Tokyo University Iraq-Iran Archaeological Expedition made an investigation during the period from January to February in 1959 in Iran from the viewpoints of archaeology and of the history of art and archtecture. At that occasion, we tried to collect archaeological materials from various ages of Iran, too. Here I would like to show a part of these collected materials, a group of figurative-shaped pottery unearthed from the vicinity of Umam in Guilan Province.

While the advance party of our team was preparing for receiving the main party, we often came across prehistoric finds of which we had never known the existence. These kinds of finds were not in the exhibition-cases of Teheran National Museum nor in many Western museums which have a lot of archaeological materials and art objects in connection with Iran, not were they found in such leading picture-books, such as A Survey of Persian Art and reports by Prof. Arthur Pope. So, our interest was attracted to these prehistoric relics. And there are two special reasons for that. The first is that, among the pottery which makes a larger part of the relics, existed some which had the common shapes with li-type, ting-type, chüch-type, i-type or ku-type pottery and bronzes of pre- and proto-historic China and the extremely similar clay material and firing condition to those of pre- and proto-historic pottery of China. Another reason is that the clay objects included some figures of goddesses and spouted pottery with shapes of the zebu or pack animals and the bronzes included figures of horse-riders, images of gods and goddesses and figures of animals, both the clay objects and bronzes being very fine examples of plastic art. It made us eager to know the place where they had come from. Curiodealers who sell articles of this kind in Teheran, called them "objects from Amrash" although they are sometimes called "objects from Pirku".

And they told us that both Amrash and Pirku are near Karaj which is located to the north-west of Teheran and that they are far in the Alborz 
Mountains. These "Amrash relics" first appeared into the curio market of Teheran last autumn and they were said to be still arriving at Teheran. Actually, while we stayed there, especially in March which is the Mohamedan New Year, a considerable amount of "Amrash relics" enlivened the curio market.

The chief objects were personal ornaments of gold or silver, beads, bronze weapons and horse-trappings, pottery and clay figures. Tne bronze weapons and horse-trappings of Amrash were similar to those of Luristan bronzes, which suggested that the former and the latter are not so different chronologically. And because some were common with "Kazbek treasure" of Caucasus and "Koban bronzes," we assumed that their date must be around 1,000 B.C. But, from the viewpoints of archaeology, objects found away from the site have little scientific worth unless the place of unearthing is clarified and the relation with other co-existing relics becomes known.

From this necessity of knowing the sites of their unearthing, two members of our party Seiichi Masuda and Takeshi Amakasu, accompanied by the Secretary of the Japanese Embassy Ito and his son, started for Amrash. When they got the village of Amrash which is on the south coast of Caspian Sea beyond the Alborz Mountains, they found that this place was not the place where the prehistoric relics were dug out, but that the "Amrash relics" were brought to Amrash from Umam 2 days travel by horse from Amrash, to send them to Teheran. So, they went to Umam on horseback, which is over $2,000 \mathrm{~m}$. above sea-level and cold in the morning and evening even in summer. In this beautiful basin of Umam with the villages among mountains, they found innumerable traces of burial sites on slopes, which had been robbed by villagers. Those sites were graves built on mountain backs, riverside terraces or on the foot of mountains, and they were of various types such as dolmen built with huge stone, burial cists composed of stone plates, pit chambers with blocks of stone laid up, and cave tombs on the hillside. It was there that we found the so-called "Amrash relics" such as bronze daggers, spearheads, armours, we found horse trappings and bells, gold and silver earrings, bracelets, personal ornaments includings agate objects and glass beads, pottery and clay figures.

Among the prehistoric relics dug out from Umam district of Guilan Province which were brought to light recently under the circumstances 
mentioned above, especially noteworthy are the figurative pottery and clay figures in the shapes of the zebu or pack animal and goddesses. Three figures of zebu (A, B, C) were included in our collection and, as to their height, A (pl. I, 1) is $23 \mathrm{~cm} ., \mathrm{B}$ (pl. I, 2), $20 \mathrm{~cm}$. and C (pl. II, 1), $24.1 \mathrm{~cm}$. A and $\mathrm{B}$ are a sort of spouted pottery to contain and pour water, while $\mathrm{C}$ is to be regarded as clay figure as it has no opening to pour in and out liquid. But without doubt the latter stylistically belongs to the same group as the former two.

The characteristic common to all of $\mathrm{A}, \mathrm{B}$ and $\mathrm{C}$ is that, giving up the reality, zebu is as much simplified and abstract in form as possible, in which its essentials are so strengthened that the result is quite successful as the plastic art. Their heads are all slim in beak-shape. In $\mathrm{A}$ and $\mathrm{B}$, the inside is a narrow groove having the function of a spout: this is not true in $C$. Many pieces of pottery with beak-like spouts like $A$ and $B$ were also found from Umam and Luristan, but they are chiefly pots. So, the beak-like spout of the zebu-shaped pottery must have come from the spouted pots which are not rare in ancient Iranian.

Another characteristic is that the forepart of the zebu is upright and a raised line runs vertically along the center of the breast, by which the intensity of this part of the body is vigorously expressed. The big hump projecting from the back is also very impressive, and, in the case of $\mathrm{A}$ and $\mathrm{B}$, it is triangular connected directly to the head part and makes the fore body-looking.

In this latter case the realism is given up and the expression of the vitality and dynamic massiveness of the animal is emphasized, while, in $\mathrm{C}$, the hump somewhat squarely rises up on the shoulder and is rather similar to nature.

The rear of the zebu is comparatively small in $\mathrm{A}, \mathrm{B}$ and $\mathrm{C}$. The fore part actually keeps balance with the all of the rest. The fact the fore body looks heavy, results in giving a strong impression that zebu is moving forward.

The tail is expressed by stylized strait line. This may have been intentionally designed to correspond to the raised line at the center of the breast. The legs are all short, having simple angular shapes.

The kind of leg shape had been common to the animal figurines in the Near East from very ancient times and shows that this old tradition of the stylistic leg survived more or less even in some large works A, B and C. The above mentioned is a general view on the zebu figures $A, B, C$, but 
there are some differences between them and they offer a variety of impressions. A is dark brown in colour and the polished surface has deep luster. Incised round patterns are dotted on the whole body except the head and leg parts. In this example, the hump is particularly sharp in triangular shape with the line of the breast, forming an intense arc, and the spout-shaped head part with two horns sticking out at its center, looks very powerful. At the same time circular dots are also responsible for giving solidity to the zebu as a whole and for making it more dynamic.

In $\mathrm{B}$, traces of the scratches of remodeling implement like spatula are seen on the yellowish brown clay. A big circular hole to pour liquid in is seen at the top of the protuberance, and the shape of the beak-like spout is very unique being cut at its thick part. As a whole, B has a more simplified and stylized from than $\mathrm{A}$ and it has a more concrete function of a liquid vessel. $\mathrm{C}$ does not have a spout at its head-part and its hump stands up independently, which means that it retains a comparatively natural form. The whole shape is composed of soft lines, and a rhythmical modeling is given to it. It differs from the vigorous style of the former two; it is a work, which well expresses the feminine in the nature of zebu.

If I am granted to express my opinion, the figures of zebu which had had something to do with the religious cult, in other words zebu figures which had chiefly been made as offerings, gradually changed themselves into the vessels for ritual use in the process of the order C-A-B, and the fact that they have the shapes of zebu must have originated from zebu's having been the sacrifical animal in the early times in north Iran.

As an example somewhat similar to them, there is a spouted pottery of pack animal loaded with leather bags $(14.5 \mathrm{~cm}$. high). Two big leather bags are on its back, one on each side of the body, and the head forms a beak-like spout. (pl. II, 2) The ears are comparatively large which make the animal look like a donkey rather than a horse. The penis is made very large for an unknown reason. The whole body is yellowish brown and polished finely. This also may not have been a vessel for a practical use but a ritual one.

We have two specimens of figures which are considered to be goddesses. (pl. III, 1 and 2) One is an independent figure and another is a figure standing on animal back. While there are differences between them, there are also, some common features: one is that the arms are quite small and are 
almost no more than traces, and the other is that the part of waist and thigh is made especially thick and fleshly.

The former (pl. III, 1) is a nude female of so called mother type, and similar ones are found widely through West Asia in the Balkans and in South Russia. But, among them, this is comparatively large and very artistically worked. This statue of the mother godess is hollowed terracotta about $15 \mathrm{~cm}$. high and it expands at its lower abdomen measuring about $5.5 \mathrm{~cm}$. It is sharp at its top of the head and the bottom of the feet. The head, abdomen and feet, all having triangular shapes and, further, the whole being a stable triangle, the structure thus composed of small and big triangles gives us a strange impression.

The eyes, nostril and mouth are expressed by small holes. A hole probably for ear-ring is on each side and a triangular hood-like head-dress is put on. Having a native face like a wood carving, it is hard to tell whether it is male or female. But from the form of breast and fat waist and abdomen, it is clear to be a statue of the mother goddess symbolizing the fertility and the productive power of the earth.

This terracotta has native sensuousness and powerful massiveness suitable to symbolize the nature of such goddess.

The latter (pl. III, 2) is a pottery forming a goddess standing on an animal. This also have a somewhat triangular shape. The height is $24.4 \mathrm{~cm}$. The face is quite peculiar. An elliptical mask-like thing just with a raised line for nose, is attached to the cylindrical head. Though it has no eyes and mouth, big ears are provided at both sides of the "mask". Numerous fine braids of hair hang down from around the cylindrical head. Five lines going around the neck, may represent necklaces. The arms are more or less reduced but are put on the breast in the manner popularly seen in the clay figures of mother goddess in West Asia and the Balkans and those of Luristan bronzes. The lower part of the body appears to be covered by Arabian trousers, and the lowest end of each foot is also surrounded by four or five lines. Though this has a evidently represented breast, it probably is not bare. It is presumed that it puts dress from the dotted lines which seems to mean the seams of the costume. The mask-like face of the figure is noteworthy, although similar expressions are seen also in clay figures of Jomon Period in Japan and black pottery figurines of the Chan-kuo Period in China. The 
animal on which the goddess stands is a cat-like animal with a mane, and represents a leopard or a lion. In West Asia, this kind of a god's image on the animal which is its attribute, originated in Hittite and was also done in Assyria and Syria of the second millenium and former part of the first millenium B.C. Therefore, this image of goddess also is what follows this style of Hittite origin, and it suggests the cultural intercourse between North Iran and the area of Anatolia and Mesopotamia in the first millenium B. C.

The dates of the above-mentioned figurative pottery and clay figures excavated from Umam and its surroundings are left unsolved at present, but many people consider that they belong to almost the same period and that the date is close to that of unearthed. But, some Sasanian objects such as gold and silver vessels, sawari vessels, gold personal ornaments, glasses, pottery and coins were also unearthed there, and the relation between these various relics and various types of tombs at Umam and the co-relation between these relics themselves are the problems which will not to be solved before the archaeological investigation of the tombs has been made.

This suggested the course of the future plan of the survey in Iran by our party from Tokyo University, and at the same time, the fact the sites where could be found the "Amrash relics" we collected in Teheran, could be roughly limited to the area around Umam, was a scientific result which very much in determing help the date and makers of the relics. For instance, Dr. Ghirshman's opinion that these may have been produced by Medians should be discussed in connection with their place of discovery. 


\section{Plate I}

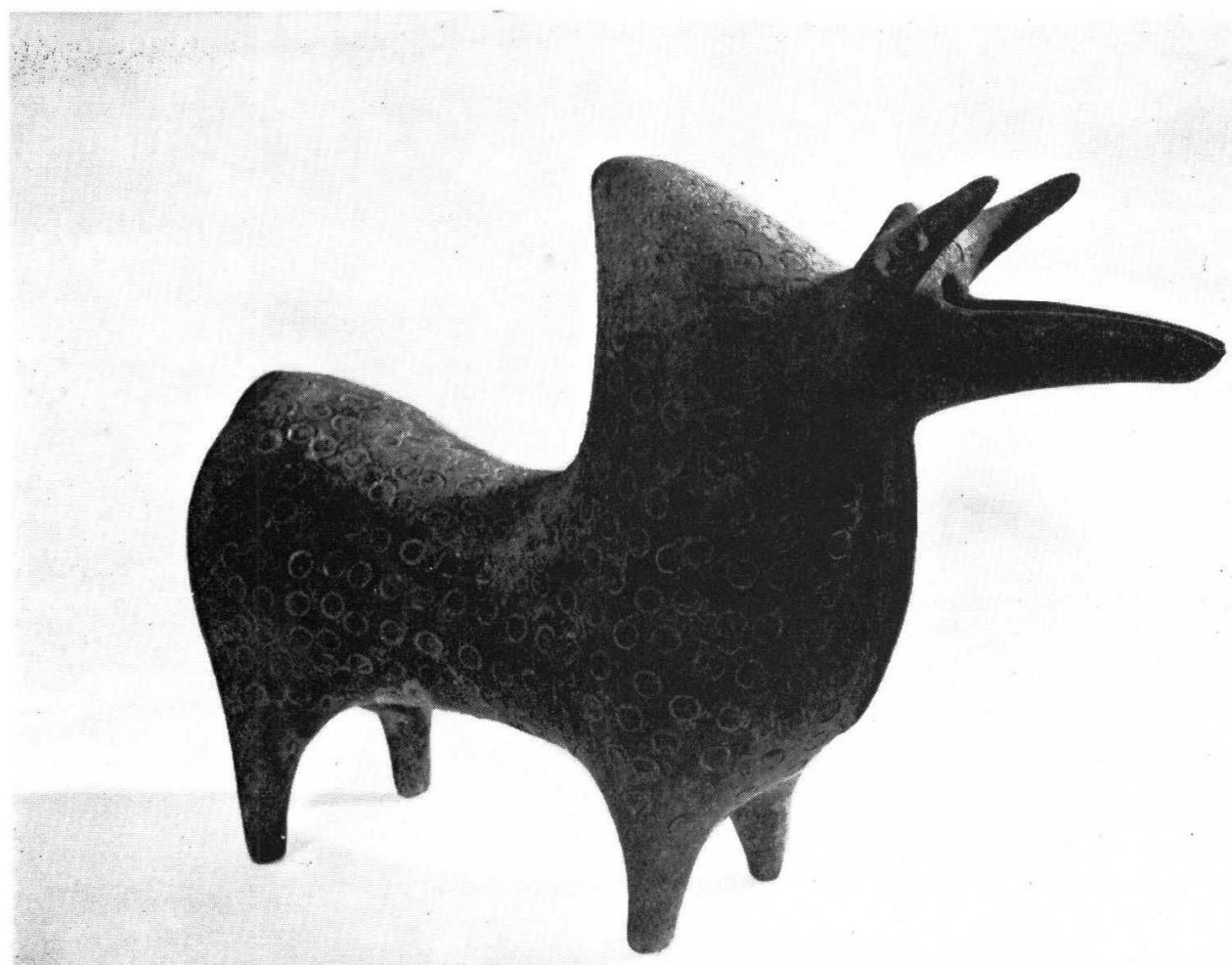

1.

2.

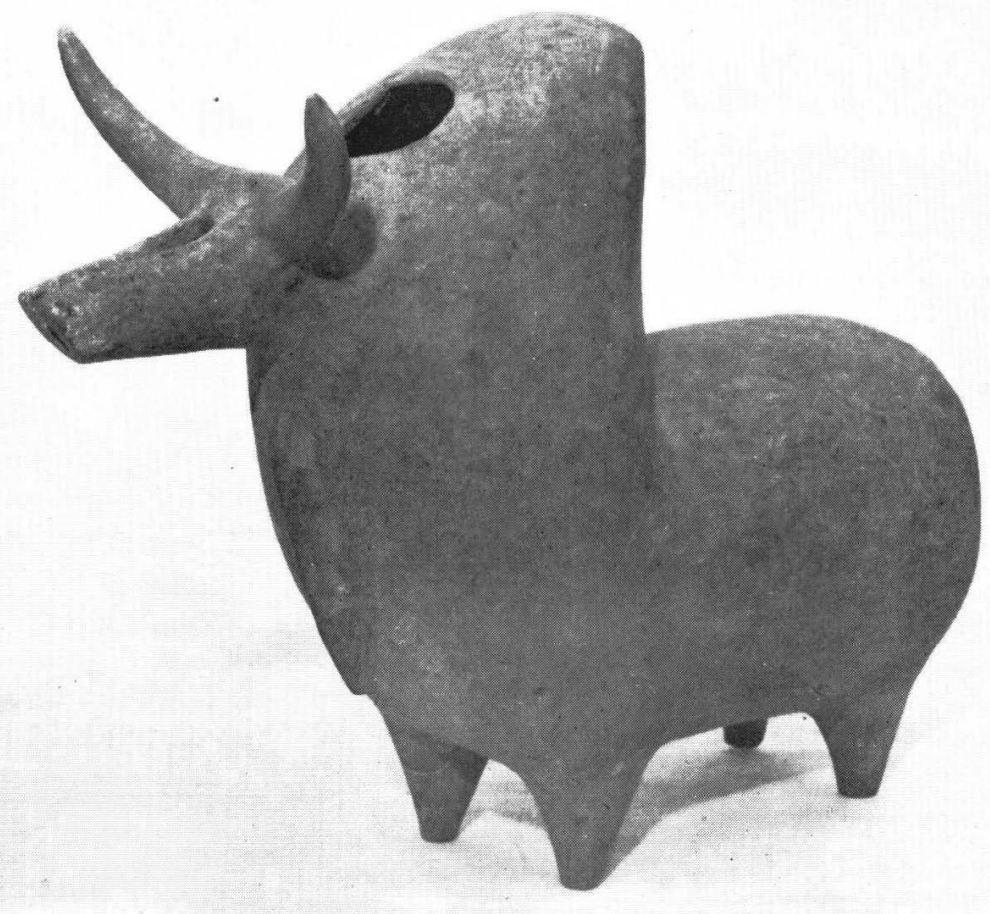


Plate II

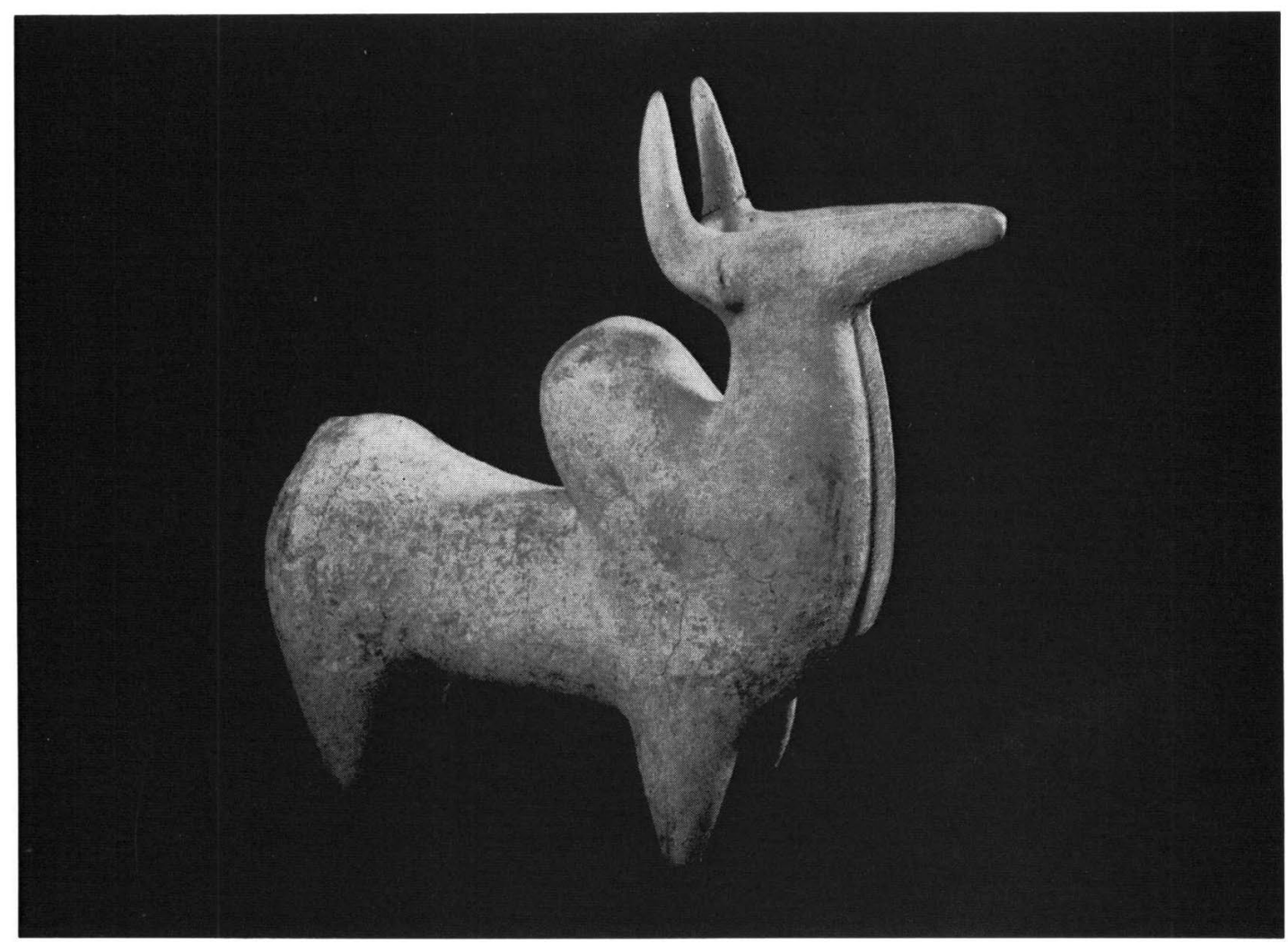

1.

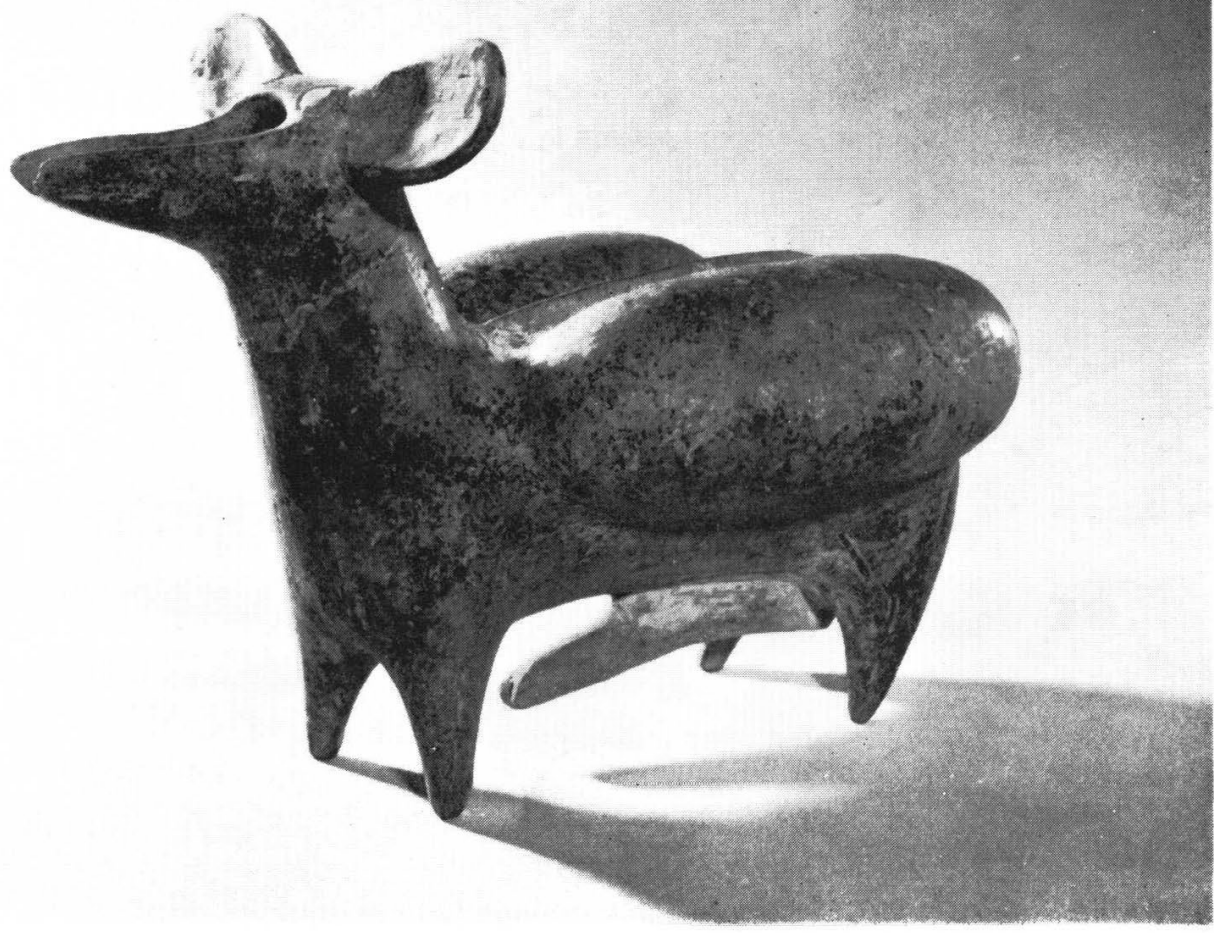




\section{Plate III}

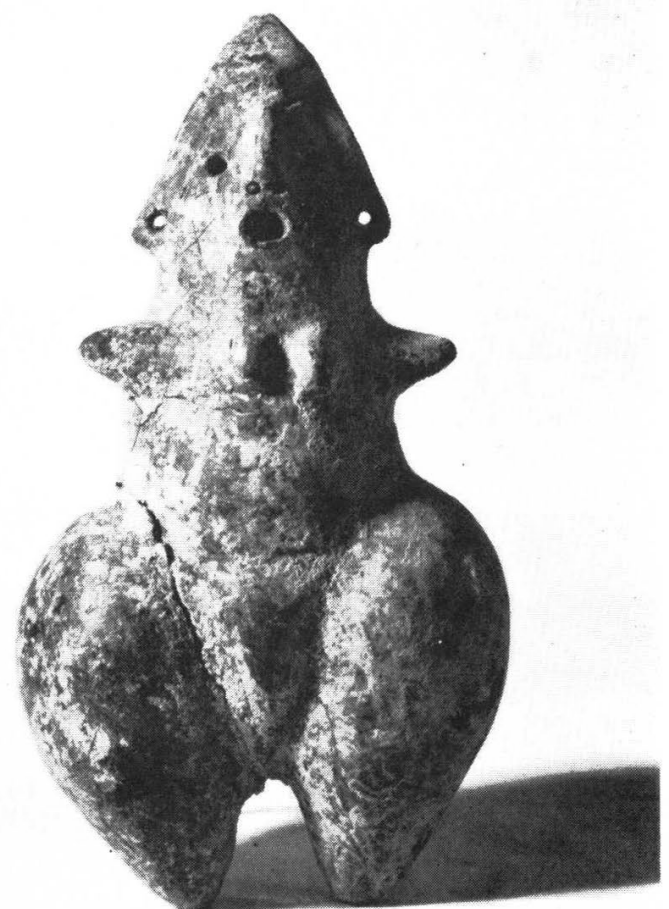

1.

2.

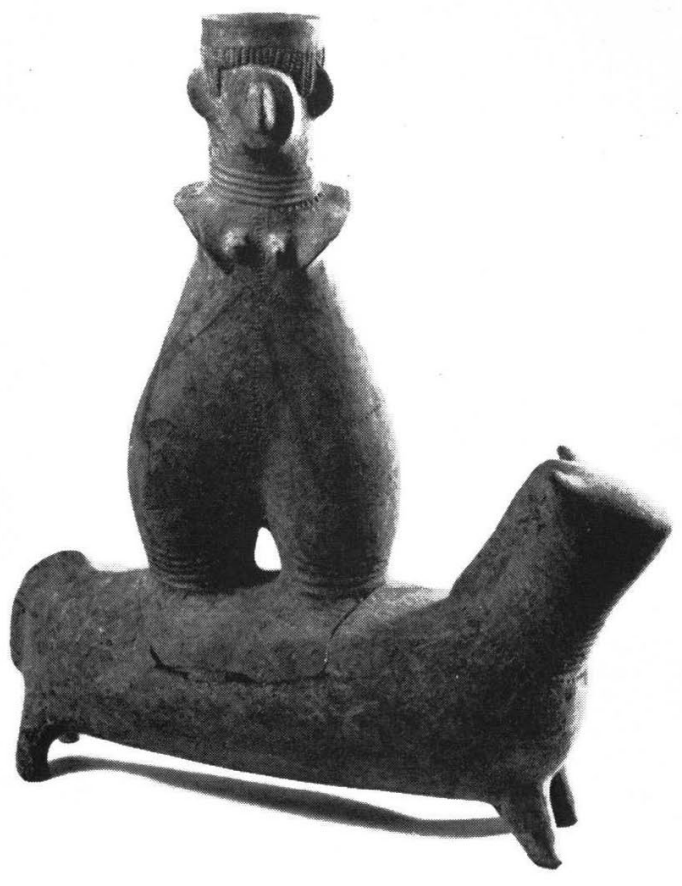

